Research Article

\title{
Analysis Method of Lactoferrin Based on Uncoated Capillary Electrophoresis
}

\author{
Hui Chen ${ }^{1}$, Zhenyu Wang ${ }^{1}$, Fengjiao Fan ${ }^{2}$, Pujie Shi ${ }^{3}$, Xianbing Xu ${ }^{1}$, Ming Du ${ }^{1}$, Cong Wang ${ }^{1,4,}$ \\ ${ }^{1}$ School of Food Science and Technology, National Engineering Research Center of Seafood, Dalian Polytechnic University, Dalian, \\ Liaoning 116034, China \\ ${ }^{2}$ College of Food Science and Engineering, Nanjing University of Finance and Economics, Nanjing, Jiangsu 210046, China \\ ${ }^{3}$ Department of Chemistry and Chemical Engineering, Harbin Institute of Technology, Harbin, Heilongjiang 150090, China \\ ${ }^{4}$ Center of Experimental Instrument, School of Food Science and Technology, Dalian Polytechnic University, Dalian 116034, \\ People's Republic of China
}

\section{ARTICLE INFO}

Article History

Received 11 April 2021

Accepted 06 July 2021

Keywords

Capillary electrophoresis lactoferrin

analytical method

auxiliary air pressure

surfactant

\section{ABSTRACT}

The analysis of lactoferrin separation will be an important application in prospect. To develop a new strategy for the detection of lactoferrin, this work adopted the method of uncoated Capillary Electrophoresis (CE), through optimizing the parameters of background electrolyte, $\mathrm{pH}$, surfactant, buffers of the system solution. The optimum lactoferrin separation by $\mathrm{CE}$ is $50 \mathrm{mM}$ phosphates buffer added $6 \mathrm{M}$ urea. In positive voltage, lactoferrin was separated by $\mathrm{CE}$ at $\mathrm{pH} 4.0$. In reverse voltage, lactoferrin can also be separated at $\mathrm{pH} 10.0$ with $50 \mathrm{mM}$ ammonium ace. The auxiliary air pressure was got involved to decrease the absorption by silica capillary through a range of gradient intensity of air pressure. By comparison with $1.2,1.5$ and 1.8 psi, the pressure of 0.5 psi can significantly alleviate the absorption. The best detection conditions of lactoferrin were obtained, which are $\mathrm{pH}$ 4.0, $50 \mathrm{mM}$ phosphates with $6 \mathrm{M}$ urea, 0.5 psi auxiliary air pressure with the limit of quantification at $0.04 \mathrm{mg} / \mathrm{mL}$ and the limit of detection at $0.01 \mathrm{mg} / \mathrm{mL}$. Finally, lactoferrin can be quantitatively detected well and effectively, which the standard curve is $y=117807 x+3018.61374$.

\section{GRAPHICAL ABSTRACT}

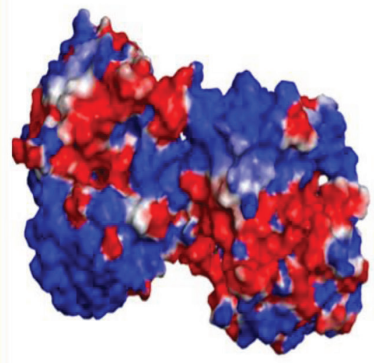

Charges distribution on the surface of lactoferrin
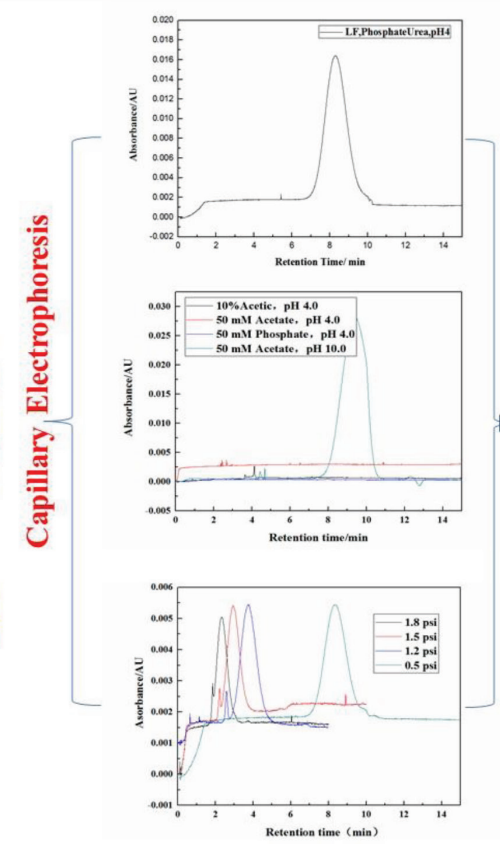

(C) 2021 The Authors. Publishing services by Atlantis Press International B.V.

This is an open access article distributed under the CC BY-NC 4.0 license (http://creativecommons.org/licenses/by-nc/4.0/).

"Corresponding author. Email: yuanque@163.com

Peer review under responsibility of the International Association of Dietetic Nutrition and Safety 


\section{INTRODUCTION}

Lactoferrin belongs to the transferrin family and has been identified in saliva, tears, mucus, pulmonary secretions, white blood cells and semen of mammals [1-4]. Lactoferrin has been widely studied in terms of its structure and biological activity. Lactoferrin is a protein composed of two leaves left and right in four polypeptide structures [5]. It is a highly glycosylated glycoprotein, and its glycosylated site is on Asn of N-terminal [6]. The main metal ions bound with lactoferrin are $\mathrm{Fe}^{2+}$ and $\mathrm{Fe}^{3+}$. More and more evidence showed that lactoferrin has important biological activities, such as antibacterial, antiviral, anti-inflammatory, antihypertensive, antioxidant, cell proliferation and differentiation, phospholipid metabolism regulation and immune regulation [5-11]. In addition, because of its iron-binding properties, lactoferrin can be a potential source of iron for breastfeeding infants. The U.S. FDA, Food Safety Commission of Japan and relevant authorities in other countries have also approved a simple and non-toxic synthesis of lactoferrin capsules for use as food additives $[12,13]$. The content limit of lactoferrin in milk products in China is $1.0 \mathrm{~g} / \mathrm{kg}$. Liquid chromatography-ultraviolet method is the main detection method for lactoferrin in the national standard in China, which the Limit of Detection (LOD) is $0.6 \mathrm{mg} / \mathrm{mL}$ [14]. According to previous reports, there are many methods to detect lactoferrin, including SDS_PAGE electrophoresis, EnzymeLinked Immunosorbent Assay (ELISA), Reversed-Phase HighPerformance Liquid Chromatography (RP-HPLC), Refractive Index Detector (RID), Surface Plasmon Resonance (SPR) and Capillary Electrophoresis (CE). SDS_PAGE electrophoresis is a traditional method for protein identification, but it requires complex and time-consuming sample pretreatment [15]. Although ELISA has high sensitivity and versatility, its repeatability is relatively poor, so there are few reports on the detection of lactoferrin by this method [16]. Lactoferrin of goat milk and their products from simulated digestion was detected by the HPLC method [17]. In low concentrations, however, the method of detection sensitivity and resolution performance is still lack, which the LOD of lactoferrin is higher than $0.05 \mathrm{mg} / \mathrm{mL}$. What's more, due to the different state of iron, lactoferrin can be divided into three subtypes (Natural, apo and holo lactoferrin) [18]. Iron ion will be changed with the RP-HPLC mobile phase gradient elution condition shifted, so the different environmental conditions may, in turn, affect the separation performance of the method $[14,17,19,20]$. HPLC-MS spectrometry has high sensitivity and selectivity in the application of analysis and detection, but due to the high detection cost of mass spectrometry, there are certain limitations on the quality control of sample detection [21]. The RID method has been used in clinical medicine and biology for many years, but is less accurate because of the complex composition of food, the immune reaction is easy to cause cross reaction, resulting in false positive results [22]. SPR technology developed in recent years is a real-time, unlabeled and automatic detection method, which has also been applied to the detection of lactoferrin in bovine colostrum, milk and formula milk powder $[23,24]$. However, this technique is based on biosensor immunoassay, expensive chips due to hard use on a large scale [25].

Though, capillary electrophoresis has been used since 1980, it has been widely used in detection analysis, such as detection of nucleic acids and proteins since its development. Capillary Zone Electrophoresis (CZE) is the most economical and commonly used separation method [26]. It works by applying a strong voltage to the capillary tube to separate electrically charged molecules utilizing a direct current electric field [27]. Capillary electrophoresis can quickly separate peptides of small molecules, whereas proteins electrovalently bound sites on their surface that can significantly bind to the silanol group on the capillary wall so that they cannot be separated. Therefore, in CE, excessive sample injection will show the phenomenon of zonal widening and unsymmetrical separation peak type. To tackle this problem, for many years, scientists have tried to use a coating of the inner capillary, or add various surfactants into separation buffer to eliminate the adsorption of silanol groups on the uncoated capillary wall. Urea, SDS, Triton and MHEC [28-32] are commonly used. In this paper, except for surfactant, the $\mathrm{pH}$ value, organic solvent, buffer, auxiliary air pressure and other conditions were optimized, and the rapid and stable analysis of lactoferrin was finally determined. It is worth mentioning that the regulation of auxiliary air pressure investigated in this paper can reduce capillary adsorption, and air pressure is a parameter rarely reported in previous studies. The results of this study are intended to provide a new perspective for the separation of lactoferrin by CE.

\section{MATERIALS AND METHODS}

\subsection{Materials and Chemicals}

The purity of lactoferrin powder (purchased from Sigma, USA) is more than 95\%. Acetonitrile (Spectrum Chemical, USA), acetic acid amine (Aladdin Industrial Corporation, Shanghai, China), SDS (Sangon Biotech Shanghai Co., Ltd., China), Triton X-100 (Sigma), Tris (BBI Life Sciences, Shanghai, China), acetic acid, phosphates, hydrochloric acid, sodium chloride, sodium hydrogen phosphates, sodium dihydrogen phosphates are bought from Aladdin Industrial Corporation.

\subsection{Sample Preparation}

Lactoferrin was weighed with an analytical balance. And the sample was added to the buffer system and dissolved by a vortex until the solution was clarified. Finally, the sample was filtrated through a $0.22-\mu \mathrm{m}$ filter with a syringe before injection. Both capillary rinsing reagent and Background Electrolyte (BGE) require ultrasonic degassing in advance.

\subsection{CE Method}

The uncoated fused capillary, inner diameter of $50 \mu \mathrm{m}$, outer diameter of $75 \mu \mathrm{m}$, length of $61.2 \mathrm{~cm}$, actual length of $51.2 \mathrm{~cm}$, was carried by a capillary electrophoresis apparatus (Beckman CESI 8000 plus, USA). Before each injection, the capillary tubes were washed and balanced by the following methods: $0.1 \mathrm{M} \mathrm{NaOH}$ washed the capillary tubes for $3 \mathrm{~min}$ at $70 \mathrm{psi}, 0.1 \mathrm{M} \mathrm{HCl}$ washed the capillary for $1 \mathrm{~min}$. Then, the capillary was washed with double distilled water for $1 \mathrm{~min}$. Finally, the capillary was washed with BGE for 5 min. Injection mode: 0.5 psi air pressure for $10 \mathrm{~s}$. The separation voltage was $+25 \mathrm{kV}$ at $20^{\circ} \mathrm{C}$, and the temperature was inclined to rise for $0.5 \mathrm{~min}$. Auxiliary pressure of 0.5 psi was separated for $20 \mathrm{~min}$, and the detection wavelength was $214 \mathrm{~nm}$. 


\subsection{Optimization of Qualitative Analysis of Lactoferrin by CE}

\subsection{1. $\mathrm{pH}$}

Under the condition of $50 \mathrm{mmol} / \mathrm{L}$ phosphates added with $6 \mathrm{~mol} / \mathrm{L}$ urea, the $\mathrm{pH}$ of $4,6,7$ and 8.9 were adjusted respectively to observe the effect on the detection sensitivity of lactoferrin.

\subsubsection{BGE systems}

To investigate the influence of surfactant on the detection effect, the following eight BGE systems were set up: $50 \mathrm{mmol} / \mathrm{L}$ phosphates solution was added with different kinds of surfactants: (a) $6 \mathrm{~mol} / \mathrm{L}$ urea; (b) $5 \mathrm{mmol} / \mathrm{L}$ Triton X-100; (c) $0.2 \%$ SDS; (d) $200 \mathrm{mM}$ Tris with $2 \%$ SDS; (e) $50 \mathrm{mM}$ ammonium acetate added $5 \mathrm{mM}$ Triton X-100; (f) $50 \mathrm{mM}$ phosphates with $6 \mathrm{M}$ urea and $5 \mathrm{mM}$ Triton X-100; (g) 50\% acetonitrile was added with $50 \mathrm{mM}$ phosphates (1:1, volume ratio); (h) $50 \mathrm{mmol} / \mathrm{L}$ acetate solution added with acetonitrile (1:1, volume ratio). The $\mathrm{pH}$ values of the above BGE systems a-c, e-h were all 4.0, and the forward voltage detection of CE was adopted. $50 \mathrm{mmol} / \mathrm{L}$ acetate solution, $\mathrm{pH} 4.0$; The $\mathrm{pH}$ of BGE system d was adjusted to 11.0, which was adopted reverse voltage detection. Under the condition of $\mathrm{pH} 4.0$, the effects of $10 \%$ acetic acid solution, $50 \mathrm{mmol} / \mathrm{L}$ ammonium acetate solution ( $\mathrm{pH} 4.0$ forward voltage, $\mathrm{pH} 10.0$ reverse voltage) and $50 \mathrm{mmol} / \mathrm{L}$ phosphates solution on the detection effect were investigated.

\subsubsection{Auxiliary air pressure}

At the same time, the $50 \mathrm{mmol} / \mathrm{L}$ phosphates solution was added with $6 \mathrm{~mol} / \mathrm{L}$ urea at $\mathrm{pH} 4.0$, assisting $0.1,0.2,0.5,1.2,1.5$ and 1.8 psi pressure, respectively. Then the effect of auxiliary air pressure on the detection effect is investigated.

\subsection{Quantitative Analysis of Lactoferrin}

The LOD/Limit of Quantification (LOQ) was determined at 3 and 10 Signal-Noise ratio $(\mathrm{S} / \mathrm{N})$ by 12 times, respectively. The analytical balance was used to weigh lactoferrin. The $10 \mathrm{~mL}$ lactoferrin reserve solution with the concentration of $1.0 \mathrm{mg} / \mathrm{mL}$ was allocated, which was gradually diluted the samples into $1.0,0.5,0.2,0.1$ and $0.04 \mathrm{mg} / \mathrm{mL}$. The method in Subsection 2.2 was used to conduct protein separation program, and the determination for each sample were repeated for three times. 32 karat software (Beckman, USA) was used to analyze the integral function of the data, and the relative concentration was quantified by the integral area at the peak time.

\subsection{Electrostatic Potential of Lactoferrin Calculated by Discovery Studio}

Lactoferrin conformation (PDB entry: $1 \mathrm{BLF}$ ) was prepared by Discovery Studio (2016, BIOVIA, USA). In brief, the conformation was cleaned and the water molecules were removed. The missing residues of the loop were supplemented base on the SEQRES records (http://www.wwpdb.org/) [33]. After that, the surface charge of lactoferrin was calculated by the program of Electrostatic Potential.

\section{RESULTS AND DISCUSSION}

\subsection{Effect of pH on Qualitative Detection of Lactoferrin}

When $50 \mathrm{mmol} / \mathrm{L}$ phosphates were added with $6 \mathrm{~mol} / \mathrm{L}$ urea, the retention time of lactoferrin in capillary tubes was delayed with the increase of $\mathrm{pH}$. This is because the closer system $\mathrm{pH}$ to the isoelectric point, the smaller the relative charge on the surface is. Therefore, under the condition of constant electric field pressure, the smaller the driving force, the smaller the electromigration is. The longer retention time, and the smaller the relative integral area is. In addition, the isoelectric point of lactoferrin is about 8.9. Although the relative charge on the surface of the system is small at this $\mathrm{pH}$, it can still drive the migration under the field intensity. In this study, the electrostatic potential of lactoferrin was calculated using a molecular dynamic program. There are some positive charge regions on the surface at $\mathrm{pH} 4.0$, shown in Figure 1. However, the higher the $\mathrm{pH}$, the smaller the integral area is. Results in Table 1 shows that the retention time of lactoferrin was 7.092 min, which was the shortest. Therefore, a comprehensive judgment shows that $\mathrm{pH} 4.0$ is further away from the isoelectric point of lactoferrin. The more ideal charged state on its surface, the more favorable for lactoferrin to migrate in the capillary.

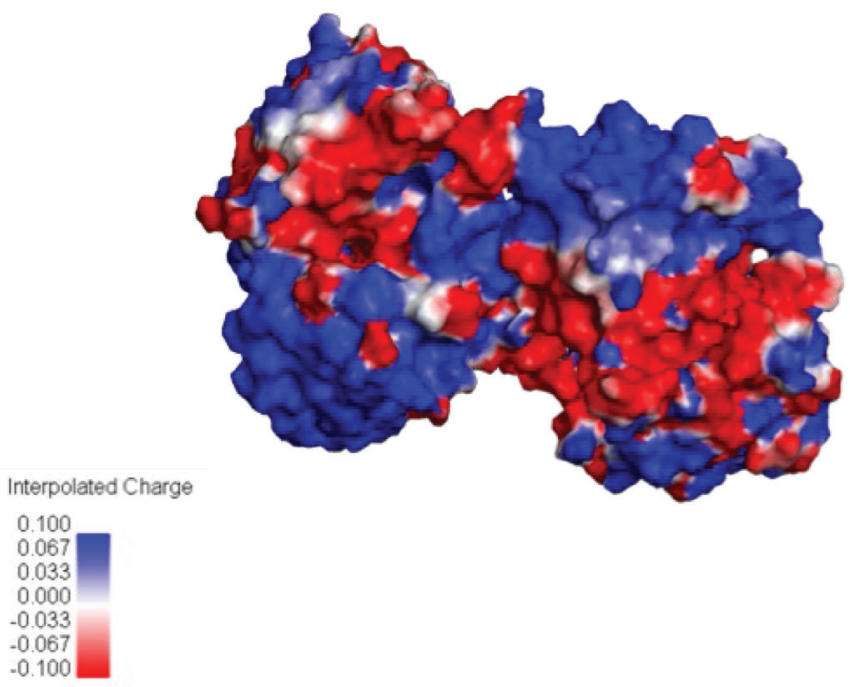

Figure 1 The electrostatic potential of lactoferrin calculated by Discovery Studio. The charge of surface was valued from -1 to +1 , which was represented by red and blue respectively.

Table 1 Comparative analysis of lactoferrin detection with different $\mathrm{pH}$

\begin{tabular}{lccc}
\hline pH & Peak width & Retention time & The integral area \\
\hline 4.0 & 3.2 & 7.092 & 43971742 \\
6.0 & 2.8 & 8.904 & 15756019 \\
7.0 & 2.4 & 9.150 & 8948407 \\
8.9 & 3.0 & 9.200 & 6554894 \\
\hline
\end{tabular}




\subsection{Effect of Surfactant on the Qualitative Detection of Lactoferrin in Forward Voltage of CE}

Adding surfactant and organic solvent into the BGE of capillary electrophoresis can change the dissolved state of the protein in the system, relieve the adsorption of the large protein to the capillary wall, and facilitate the separation and detection. As can be

a

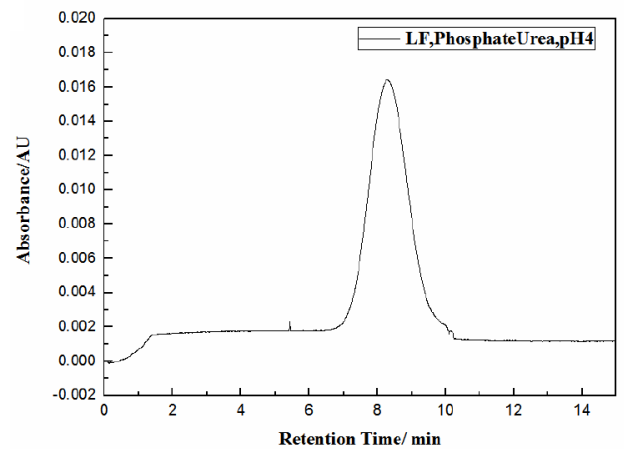

c
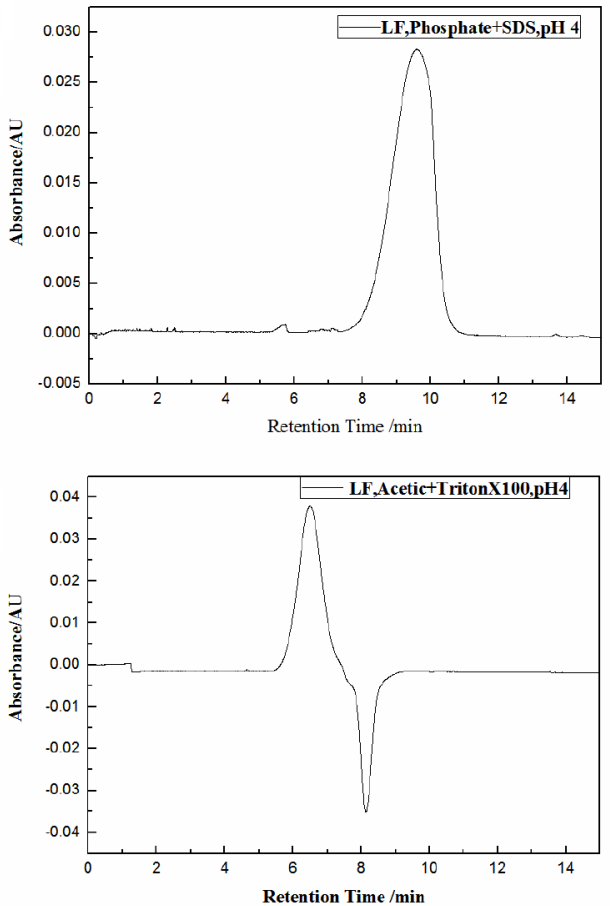

g

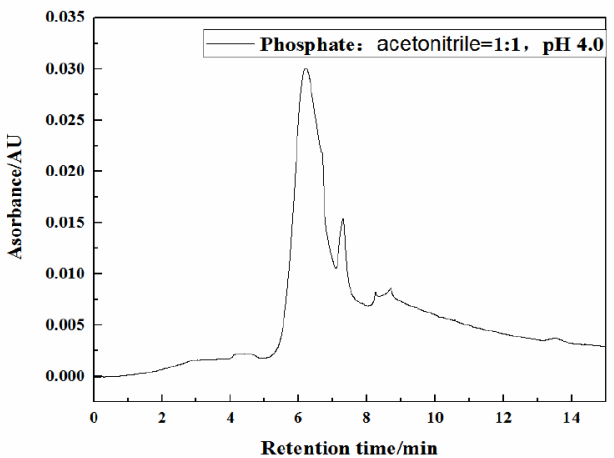

seen in Figure 2, only urea can achieve good detection and has a good peak shape for BGE with different surfactants and organic solvents. Urea has been added to the BGE system in many studies of whey protein in capillary separation of dairy products. This may be because the high concentration of urea can break hydrogen bonds, increase the solubility of hydrophobic amino acids in the water phase and reduce the adsorption phenomenon. The addition of Triton X-100 will lead to the solvent peak followed by the main

b
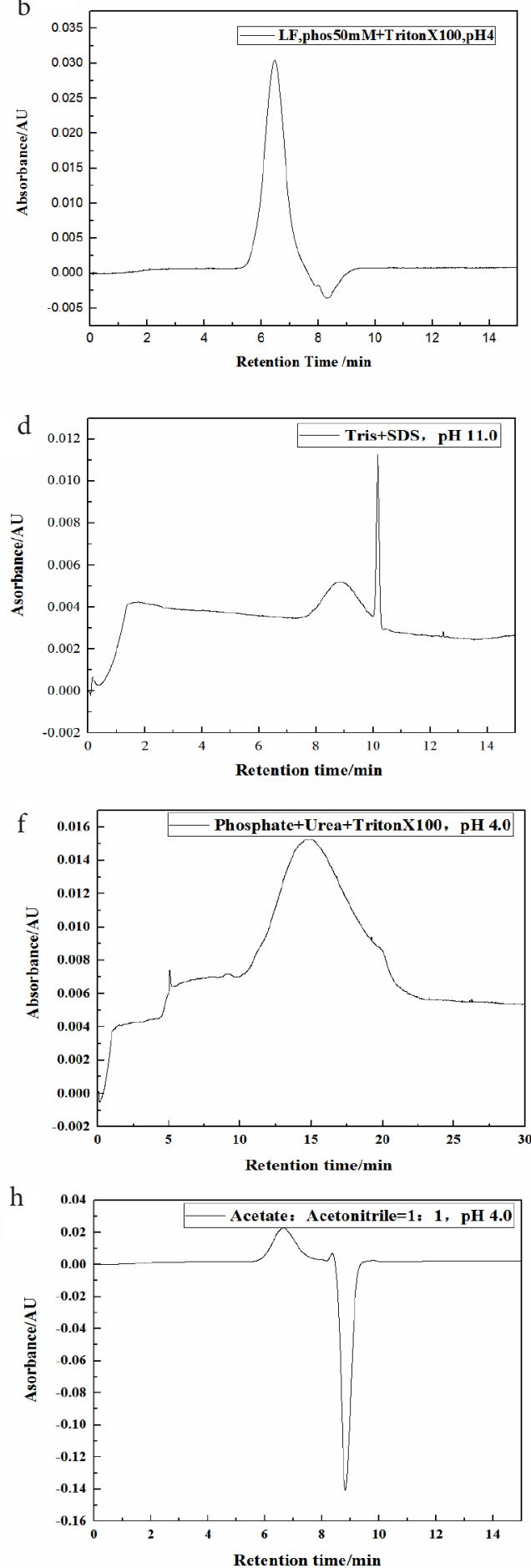

Figure 2 Lactoferrin spectra of different additive detection. (a-c), $6 \mathrm{M}$ urea, Triton X-100 of $5 \mathrm{mM}, 0.2 \%$ SDS were added to phosphates of $50 \mathrm{mM}$ at pH 4.0. (d) $200 \mathrm{mM}$ Tris with $2 \% \mathrm{SDS}, \mathrm{pH}$ 11.0. (e) $50 \mathrm{mM}$ ammonium acetate added $5 \mathrm{mM}$ Triton X-100, pH 4.0; (f) $50 \mathrm{mM}$ phosphates with $6 \mathrm{M}$ urea and $5 \mathrm{mM}$ Triton X-100, pH 4.0; ( $\mathrm{g}$ and h) 50\% acetonitrile was added with $50 \mathrm{mM}$ phosphates and $50 \mathrm{mM}$ ammonium acetate, respectively, at pH 4.0 . 
peak, and the addition of SDS will lead to the peak type asymmetry and abnormal peak $[3,34]$. Triton, as a nonionic surfactant, can alleviate electroosmosis in dynamically coated capillarity, but this result shows that it may not improve the peak shape. However, the addition of organic solvent can lead to solvent peak, or bifurcation and trailing, and the organic solvent can cause the change of polarity in the system, thereby affecting the stability of lactoferrin dissolution. This result has also been proved in peer studies [18,25]. For comprehensive consideration, adding $6 \mathrm{~mol} / \mathrm{L}$ urea to $50 \mathrm{mmol} / \mathrm{L}$ phosphates at $\mathrm{pH} 4.0$ was the most advantageous among all alternatives for the detection of lactoferrin.

\subsection{Qualitative Detection of Lactoferrin in Backward Voltage of CE}

It has been proved by the theory that when the $\mathrm{pH}$ of the system is higher than the isoelectric point of the protein, the protein in the system will have a negative charge, so it can repel the ionized and negatively charged capillary wall without adsorption. In this case, the reverse voltage of capillary electrophoresis would be conducive to the protein movement. It has been reported in the literature that the separation of 12 amino acid synthetic peptides was realized on reverse voltage [35]. In this study, lactoferrin was also detected at a reverse voltage of $-25 \mathrm{kV}$ by using an amine acetate system with $\mathrm{pH}$ 10.0 and without surfactant added. However, another three buffers at $\mathrm{pH} 4.0$, in forward voltage, without any surfactant system, cannot separate lactoferrin. It suggests that at the $\mathrm{pH}$ below the isoelectric point, the surface of the protein positively charged, so lactoferrin cannot be separated through uncoated capillary on forward voltage in absence of surfactant, as shown in Figure 3.

\subsection{Effect of Auxiliary Air Pressure on Lactoferrin Detection}

Lactoferrin was not detected at the auxiliary pressure of 0.1 and 0.2 psi, until lactoferrin was successfully detected as auxiliary pressure

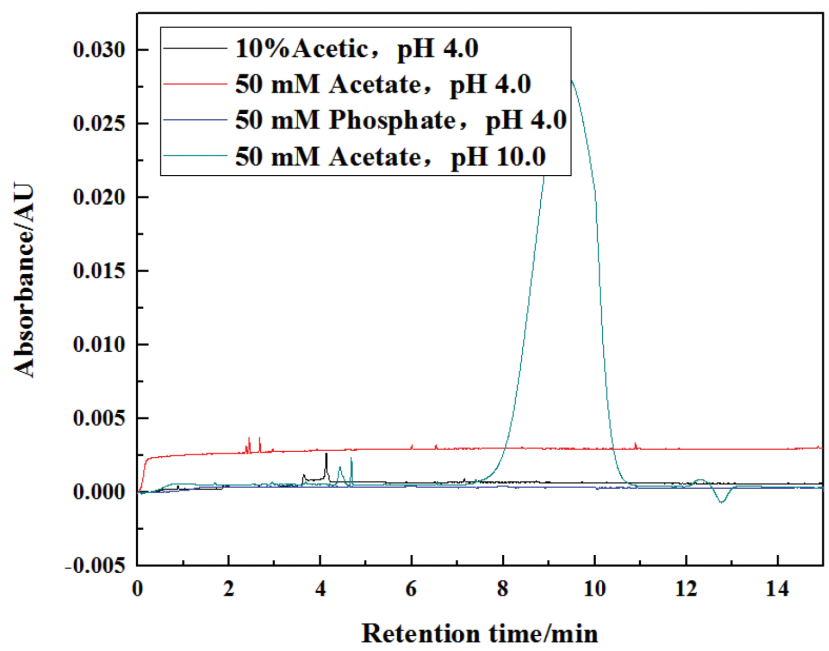

Figure 3 Lactoferrin spectra of detection in reverse voltage with acetic amine system at $\mathrm{pH} 10.0$. The $50 \mathrm{mmol} / \mathrm{L}$ ammonium acetate and $\mathrm{pH} 10.0$ system was tested by reverse voltage, while the $10 \%$ acetic acid, $50 \mathrm{mM}$ ammonium acetate and $50 \mathrm{mM}$ phosphates system were tested by forward voltage at $\mathrm{pH} 4.0$. comes at 0.5 psi. As can be seen from the results in Figure 4 and Table 2, with the increase of auxiliary air pressure, the retention time was gradually shortened, and the corresponding integral area at the peak time was also gradually reduced. Too much auxiliary pressure, such as 1.2, 1.5 and $1.8 \mathrm{psi}$, indeed reduced the retention time hardly, however, it also affected the accuracy of lactoferrin detection. Therefore, the auxiliary pressure of 0.5 psi is the most ideal for lactoferrin detection. Mine et al. [36,37] also reported that 50 mbar (the equivalent of $0.725 \mathrm{psi}$ ) air pressure was utilized in $\mathrm{CE}$ for the fast detection of creatine kinase and carboxylesterase, indicating that the enzyme adsorption by the capillary wall was improved effectively. However, in this study, auxiliary pressure using to detect lactoferrin is smaller.

\subsection{Determination of Lactoferrin Quantitative Method}

According to the above test results, the best buffer system was determined to be $50 \mathrm{mmol} / \mathrm{L}$ phosphates with $6 \mathrm{~mol} / \mathrm{L}$ urea, which could not only alleviate the adsorption of the capillary wall, but also improve the peak shape. Although the reverse voltage method successfully detect lactoferrin, the symmetry of the peak pattern is not symmetrical enough. The auxiliary pressure of 0.5 psi can accelerate the movement of the sample, and the retention time was more reasonable, as shown in Figure 5. Under this condition,

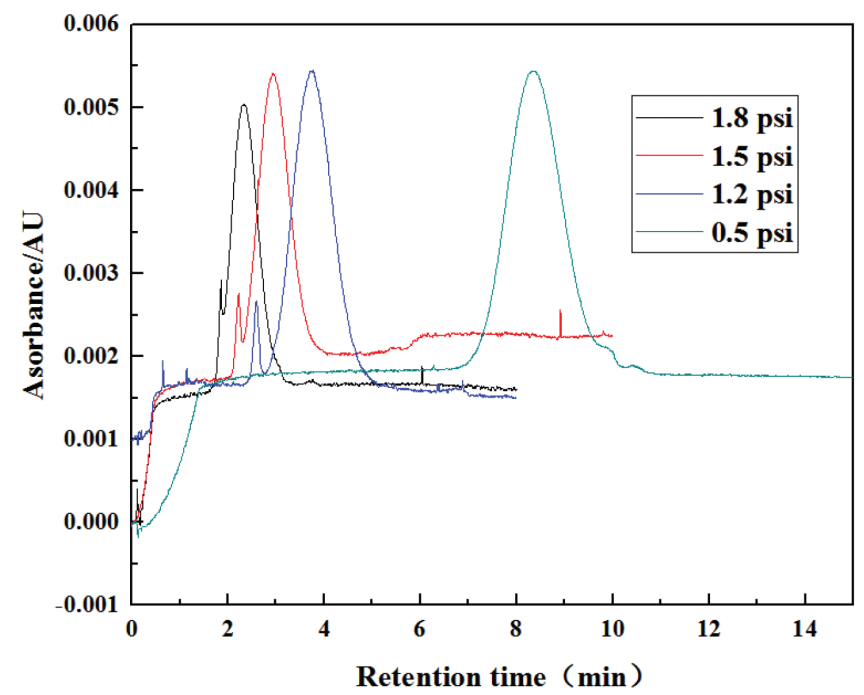

Figure 4 Lactoferrin spectra of detection with different auxiliary air pressure of capillary electrophoresis. The phosphates solution of $50 \mathrm{mM}$ with $6 \mathrm{M}$ urea, at $\mathrm{pH} 4.0$, assisted by $0.5,1.2,1.5$ and 1.8 psi pressure, respectively.

Table 2 Comparative analysis result of lactoferrin detection in the same buffer solution with different auxiliary air pressure

\begin{tabular}{lccc}
\hline $\begin{array}{l}\text { Auxiliary } \\
\text { pressure (psi) }\end{array}$ & Peak width & $\begin{array}{c}\text { Retention } \\
\text { time }\end{array}$ & The integral area \\
\hline 0.5 & 3.2 & 8.325 & 306714 \\
1.2 & 2.8 & 3.763 & 254317 \\
1.5 & 2.1 & 2.925 & 218686 \\
1.8 & 1.5 & 2.308 & 135793 \\
\hline
\end{tabular}




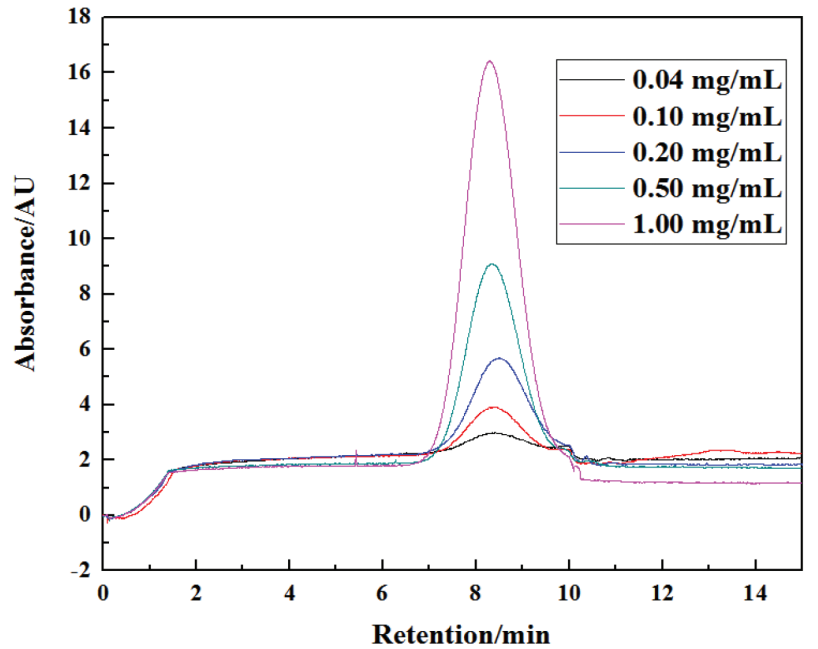

b

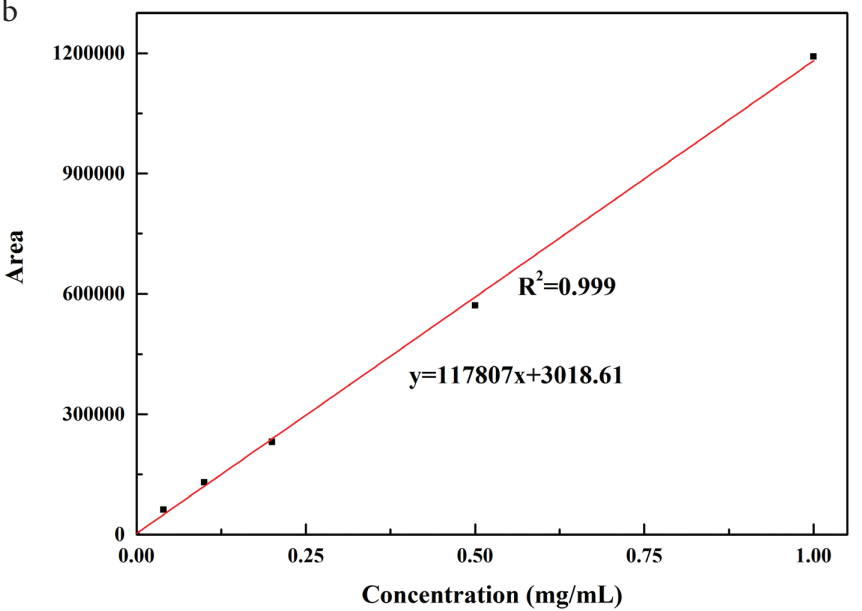

Figure 5 The standard curve of Lactoferrin. (a) Lactoferrin absorption peak at different concentrations; (b) Standard curve of detector response and time with different lactoferrin concentrations.

lactoferrin can be quantitatively detected, which the standard curve is $y=117807 x+3018.61374$, with the fitting $R^{2}=0.999$. And in this method, the LOQ and LOD of lactoferrin detected by CE was at 0.04 and $0.01 \mathrm{mg} / \mathrm{mL}$ respectively.

\section{CONCLUSION}

In this research, the separation of lactoferrin by CZE with uncoated molten capillary was studied. The effect of system $\mathrm{pH}$, surfactant, organic solvent, buffer system and auxiliary air pressure on the separation of lactoferrin by CZE was investigated. Capillary electrophoresis is a sensitive analytical technique, but the parameters that affect the separation effect are relatively broad. This study investigated the influence factor of capillary electrophoresis, which involves less auxiliary air pressure, which illustrates that adjusting the auxiliary air pressure can improve the peak shape, slow down the adsorption resistance and accelerate the detection. The standard curve for the determination of lactoferrin at optimum auxiliary pressure was obtained. This result may provide a new perspective for the application of protein separation with the help of uncoated capillary electrophoresis.

\section{CONFLICTS OF INTEREST}

The authors declare they have no conflicts of interest.

\section{AUTHORS' CONTRIBUTION}

$\mathrm{HC}$ and $\mathrm{ZW}$ performed the experiment. FF and PS contributed to manuscript preparation. $\mathrm{XX}$ and $\mathrm{MD}$ performed the data analysis. $\mathrm{CW}$ contributed to the experiment design and the discussions.

\section{ACKNOWLEDGMENTS}

All the authors contributed to the works thank the financial support of National Natural Science Foundation of China (31771926, 31730069) and the State Key Research and Development Plan "Modern Food Processing and Food Storage and Transportation Technology and Equipment" (2017YFD0400201).

\section{REFERENCES}

[1] Chung TDY, Raymond KN. Lactoferrin: the role of conformational changes in its iron binding and release. J Am Chem Soc 1993;115:6765-8.

[2] Masson PL, Heremans JF, Dive CH. An iron-binding protein common to many external secretions. Clin Chim Acta 1966;14:735-9.

[3] Teo A, Goh KKT, Wen J, Oey I, Ko S, Kwak HS, et al. Physicochemical properties of whey protein, lactoferrin and Tween 20 stabilised nanoemulsions: effect of temperature, $\mathrm{pH}$ and salt. Food Chem 2016;197:297-306.

[4] Hutchens TW, Henry JF, Yip TT. Purification and characterization of intact lactoferrin found in the urine of human milk-fed preterm infants. Clin Chem 1989;35:1928-33.

[5] Siqueiros-Cendón T, Arévalo-Gallegos S, Iglesias-Figueroa BF, García-Montoya IA, Salazar-Martínez J, Rascón-Cruz Q. Immunomodulatory effects of lactoferrin. Acta Pharmacol Sin 2014;35:557-66.

[6] Karav S, German JB, Rouquié C, Le Parc A, Barile D. Studying lactoferrin N-glycosylation. Int J Mol Sci 2017;18:870.

[7] Ono T, Morishita S, Murakoshi M. Novel function of bovine lactoferrin in lipid metabolism: visceral fat reduction by enteric-coated lactoferrin. PharmaNutrition 2013;1:32-4.

[8] Ono T, Murakoshi M, Suzuki N, Iida N, Ohdera M, Iigo M, et al. Potent anti-obesity effect of enteric-coated lactoferrin: decrease in visceral fat accumulation in Japanese men and women with abdominal obesity after 8-week administration of enteric-coated lactoferrin tablets - CORRIGENDUM. Br J Nutr 2015;114:159.

[9] Du M, Liu M, Fan F, Shi P, Tu M. Structure, function, and nutrition of lactoferrin. In: Zhao G, editor. Mineral containing proteins. Singapore: Springer; 2017, pp. 33-61.

[10] Manzoni P, Meyer M, Stolfi I, Rinaldi M, Cattani S, Pugni L, et al. Bovine lactoferrin supplementation for prevention of necrotizing enterocolitis in very-low-birth-weight neonates: a randomized clinical trial. Early Hum Dev 2014;90:S60-S5.

[11] Fernández-Musoles R, Salom JB, Martínez-Maqueda D, López-Díez JJ, Recio I, Manzanares P. Antihypertensive 
effects of lactoferrin hydrolyzates: inhibition of angiotensin- and endothelin-converting enzymes. Food Chem 2013;139:994-1000.

[12] Kilic E, Novoselova MV, Lim SH, Pyataev NA, Pinyaev SI, Kulikov $\mathrm{OA}$, et al. Formulation for oral delivery of lactoferrin based on bovine serum albumin and tannic acid multilayer microcapsules. Sci Rep 2017;7:44159.

[13] Balcão VM, Costa CI, Matos CM, Moutinho CG, Amorim M, Pintado ME, et al. Nanoencapsulation of bovine lactoferrin for food and biopharmaceutical applications. Food Hydrocoll 2013;32:425-31.

[14] Zhang Y, Lou F, Wu W, Dong X, Ren J, Shen Q. Determination of bovine lactoferrin in food by HPLC with a heparin affinity column for sample preparation. J AOAC Int 2017;100:133-8.

[15] Freeman KL, Anderson DC, Hughes B, Buffone GJ. Rapid radiometric assay used to asses lactoferrin in granulocytes. Clin Chem 1985;31:407-9.

[16] Rautenberg W, Neumann S, Gunzer G, Lang H, Jochum M, Fritz H. Quantitation of human lactoferrin as an inflammation marker by an enzyme-linked immunosorbent assay (ELISA). Z Anal Chem 1986;324:364.

[17] Yao X, Bunt C, Cornish J, Quek SY, Wen J. Improved RP-HPLC method for determination of bovine lactoferrin and its proteolytic degradation in simulated gastrointestinal fluids. Biomed Chromatogr 2013;27:197-202.

[18] Nowak P, Śpiewak K, Nowak J, Brindell M, Woźniakiewicz M, Stochel G, et al. Selective separation of ferric and non-ferric forms of human transferrin by capillary micellar electrokinetic chromatography. J Chromatogr A 2014;1341:73-8.

[19] Tsakali E, Petrotos K, Chatzilazarou A, Stamatopoulos K, D’Alessandro AG, Goulas P, et al. Short communication: determination of lactoferrin in Feta cheese whey with reversed-phase high-performance liquid chromatography. J Dairy Sci 2014;97:4832-7.

[20] Palmano KP, Elgar DF. Detection and quantitation of lactoferrin in bovine whey samples by reversed-phase high-performance liquid chromatography on polystyrene-divinylbenzene. J Chromatogr A 2002;947:307-11.

[21] Ke X, Chen Q, Pan X, Zhang J, Mo W, Ren Y. Quantification of lactoferrin in breast milk by ultra-high performance liquid chromatography-tandem mass spectrometry with isotopic dilution. RSC Adv 2016;6:12280-5.

[22] Gong GY, Qing-Hua WU, Zheng-Jun WU. A lactoferrin determination-radial immunodiffusion method. China Dairy Ind 2001;29:27-9.

[23] Indyk HE, Filonzi EL. Determination of lactoferrin in bovine milk, colostrum and infant formulas by optical biosensor analysis. Int Dairy J 2005;15:429-38.

[24] Billakanti JM, Fee CJ, Lane FR, Kash AS, Fredericks R. Simultaneous, quantitative detection of five whey proteins in multiple samples by surface plasmon resonance. Int Dairy J 2010;20:96-105.

[25] Li J, Ding X, Chen Y, Song B, Zhao S, Wang Z. Determination of bovine lactoferrin in infant formula by capillary electrophoresis with ultraviolet detection. J Chromatogr A 2012;1244: 178-83.

[26] Caslavska J, Lanz C, Burda P, Tobler M, Thormann W. Analysis of genetic variants of transferrin in human serum after desialylation by capillary zone electrophoresis and capillary isoelectric focusing. J Sep Sci 2017;40:2488-97.

[27] Green JS, Jorgenson JW. Minimizing adsorption of proteins on fused silica in capillary zone electrophoresis by the addition of alkali metal salts to the buffers. J Chromatogr A 1989;478:63-70.

[28] Cohen AS, Karger BL. High-performance sodium dodecyl sulfate polyacrylamide gel capillary electrophoresis of peptides and proteins. J Chromatogr A 1987;397:409-17.

[29] Recio I, Amigo L, López-Fandiño R. Assessment of the quality of dairy products by capillary electrophoresis of milk proteins. J Chromatogr B Biomed Appl 1997;697:231-42.

[30] Salas-Solano O, Tomlinson B, Du S, Parker M, Strahan A, Ma S. Optimization and validation of a quantitative capillary electrophoresis sodium dodecyl sulfate method for quality control and stability monitoring of monoclonal antibodies. Anal Chem 2006;78:6583-94.

[31] Guttman A. Capillary sodium dodecyl sulfate-gel electrophoresis of proteins. Electrophoresis 1996;17:1333-41.

[32] Jorgenson JW, Lukacs KD. Capillary zone electrophoresis. Science 1983;222:266-72.

[33] Li Y, Su M, Liu Z, Li J, Liu J, Han L, et al. Assessing protein-ligand interaction scoring functions with the CASF-2013 benchmark. Nat Protoc 2018;13:666-80.

[34] Watanabe N, Shirakawa T, Iwahashi M, Seimiya T. Effect of surface charge on adsorption of bovine serum albumin 2. Interaction of protein molecules with an anionic monolayer, as studied by ellipsometry, radiotracer and surface tension measurements. Colloid Polymer Sci 1988;266:254-60.

[35] Yang Y, Boysen RI, Hearn MTW. Analysis of synthetic peptides by capillary electrophoresis: effect of organic solvent modifiers and variable electrical potentials on separation efficiencies. J Chromatogr A 2004;1043:91-7.

[36] Mine M, Mizuguchi H, Takayanagi T. Kinetic analysis of the transphosphorylation with creatine kinase by pressure-assisted capillary electrophoresis/dynamic frontal analysis. Anal Bioanal Chem 2021;413:1453-60.

[37] Mine M, Matsumoto N, Mizuguchi H, Takayanagi T. Kinetic analysis of an enzymatic hydrolysis of $p$-nitrophenyl acetate with carboxylesterase by pressure-assisted capillary electrophoresis/ dynamic frontal analysis. Anal Methods 2020;12:5846-51. 